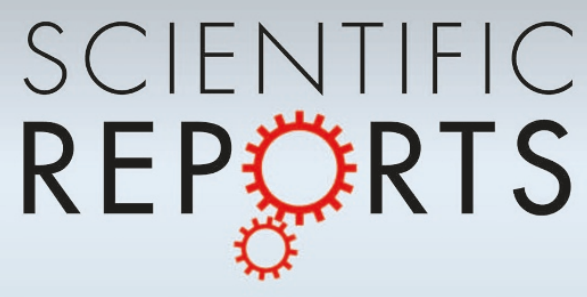

\title{
One-Dimensional $\mathrm{Al}_{4} \mathrm{O}_{4} \mathrm{C}$ Ceramics:
} A New Type of Blue Light Emitter

SUBJECT AREAS:

CERAMICS

NANOWIRES

STRUCTURAL PROPERTIES

NANOPHOTONICS AND PLASMONICS

Received

27 February 2013

Accepted

10 April 2013

Published

29 April 2013

Correspondence and requests for materials should be addressed to

C.X.W. (wchengx@ mail.sysu.edu.cn)

\author{
Yong Sun', Yuanzheng Chen'², Cairong Ding', Guowei Yang', Yanming $\mathrm{Ma}^{2} \&$ Chengxin Wang'
}

'State key laboratory of optoelectronic materials and technologies, School of Physics Science and Engineering, Sun Yat-sen (Zhongshan) University, Guangzhou 510275, People's Republic of China, ${ }^{2}$ State Key Lab of Superhard Materials, Jilin University, Changchun 130012, People's Republic of China

Ceramic $\mathrm{Al}_{4} \mathrm{O}_{4} \mathrm{C}$, which has few active functions, has been used as an additive in carbon-containing refractory materials to improve their oxidation resistance and thermal properties. Herein, the crystal and electronic structures of this novel material were systematically investigated for opto-electrical applications, which revealed interesting fluorescence features via photoluminescence (PL) and cathode luminescence (CL). When a $325 \mathrm{~nm}$ laser was focused on one end of a single $\mathrm{Al}_{4} \mathrm{O}_{4} \mathrm{C}$ needle, the entire needle was illuminated by the blue emission, which implies that this material exhibits excellent waveguide properties. Interestingly, the thin end exhibited the highest light intensity even though the excited region was located at the thick end. We believe the reason for this observed behaviour is related to the excellent waveguide behaviour as well as to the needle shape, which induces this intriguing blue-light convergence effect. Ab initio calculations demonstrated that the emission light emanates from the interband transition.
T he rapid growth of industry in modern society provides us with ever-increasing numbers of highly tech nological products that make our lives more convenient. Researchers have created liquid-crystal displays (LCDs) as well as telecommunication, artificial intelligence and clean-energy devices due to the emergence of various new functional materials. Because of the extensive focus of researchers on semiconductor materials, such as $\mathrm{ZnO}^{1-5}$ and $\mathrm{GaN}^{6-8}$, attractive properties have been discovered and applied to commercial products. In the same way, it is important to focus our attention on the design of new materials and the exploitation of lesserknown materials that exhibit novel properties.

Previously, we investigated the potential photoelectric functionality of Al-C-based mechanical ceramic materials, such as $\mathrm{Al}_{4} \mathrm{C}_{3}{ }^{9-11}$ and $\mathrm{Al}_{3} \mathrm{CON}^{12}$. For $\mathrm{Al}_{4} \mathrm{C}_{3}$, we synthesised various 1-D nanostructures and reported their potential application as field electron emitters. We systematically investigated the mechanical properties and photoelectric response behaviour of a single $\mathrm{Al}_{3} \mathrm{CON}$ nanobelt. Recently, we introduced oxygen into the $\mathrm{Al}-\mathrm{C}$ based material, which resulted in the formation of $\mathrm{Al}_{4} \mathrm{O}_{4} \mathrm{C} . \mathrm{Al}_{4} \mathrm{O}_{4} \mathrm{C}$ exhibits properties typical of a ceramic material, such as a high melting point. In general, ceramic materials of $\mathrm{Al}_{4} \mathrm{O}_{4} \mathrm{C}$ are used as an additive in carbon-containing refractory materials to improve their oxidation resistance and thermal properties, and they are commonly synthesised via the solid-state reaction method at temperatures as high as $2000^{\circ} \mathrm{C}^{13,14}$. Although little attention has been focused on this material, this type of ternary oxide would be of great use in the photoelectric field because of its characteristics. Because of the introduction of carbon atoms, the electrons of $\mathrm{Al}_{4} \mathrm{O}_{4} \mathrm{C}$ are not as inert as those of $\mathrm{Al}_{2} \mathrm{O}_{3}$, exhibit characteristics similar to those of wide band gap semiconductor materials and possess highly efficient light emission properties. Therefore, $\mathrm{Al}_{4} \mathrm{O}_{4} \mathrm{C}$ is a potential candidate for use as a photoelectric functional material, especially to meet the demands of modern society for a highly efficient blue light source.

In this work, we report the synthesis of needle-like $\mathrm{Al}_{4} \mathrm{O}_{4} \mathrm{C}$ micro-nano structures that exhibit intense blue light emission behaviour even under a weakly excited condition. Using a confocal microscope coupled with a CCD (Charge-coupled Device), we recorded a light-emitting image that corresponds to a single structure under $325 \mathrm{~nm}$ laser irradiation, which suggests that $\mathrm{Al}_{4} \mathrm{O}_{4} \mathrm{C}$ is a waveguide-type material in which the emission light is transported along the needle structure and converges at the thin end, similar to a convex. A xenon lamp was employed as the light source to excite the sample, which resulted in high-intensity blue emission that is visible to the human eye. Different spectra collected under the same excited condition at various temperatures $(12 \mathrm{~K}-$ $300 \mathrm{~K}$ ) were recorded. Under a scanning electron microscope operating platform, a needle was excited with a cathode electron beam. In addition, using the ab initio method, we calculated the Raman spectrum of $\mathrm{Al}_{4} \mathrm{O}_{4} \mathrm{C}$, which is in good agreement with the experimental results. The band gap obtained from electronic structure 
calculations was approximately $3.8 \mathrm{eV}$, which demonstrates that the light emission may occur from the electronic transition from the conduction-band minimum to the valence band maximum.

\section{Results}

Characterisation of $\mathrm{Al}_{4} \mathrm{O}_{4} \mathrm{C}$ micro-nano needles. The morphology investigation was performed using SEM (scanning electron microscopy), as shown in Fig. 1. Figs. 1a and $1 \mathbf{b}$ show typical lowmagnification images, which indicate the distribution of the $\mathrm{Al}_{4} \mathrm{O}_{4} \mathrm{C}$ needle wires. All of the wires lay uniformly on the Si substrate after being transferred from the ceramic sheet. Figs. $\mathbf{1}(\mathbf{c}-\mathbf{h})$ show a single wire with different sizes and shapes. All of the wires exhibit a needle shape with catalytic droplets at the thick end. In addition, some of the nanowires have irregular shapes, such as curved bodies. In fact, the sizes of the needle wires are restricted by the catalytic heads, and the final shapes are also controlled by the catalytic droplet motion, both the size and shape of the wires originate from the growth mechanism illustrated below.

Structural analysis of the product was performed using X-ray diffraction (XRD, Bruker D8 Advance) after it was transferred from the ceramic sheet to the silicon substrate, and the results are shown in Fig. 2. The main signal peaks were attributed to $\mathrm{Al}_{4} \mathrm{O}_{4} \mathrm{C}(\mathrm{PDF} \# 48$ 1583) and are marked by the blue lines. In addition, weak signals corresponding to $\mathrm{Al}_{2} \mathrm{O}_{3}$ and $\mathrm{Al}$ were also detected. These signals are indicated by lines with different colours, as shown in Fig. 2a. Based on the lattice parameter and atomic coordinates, we determined the optimised structure of $\mathrm{Al}_{4} \mathrm{O}_{4} \mathrm{C}$, which is shown in the inset in Fig. 2.

The phonon calculations were performed using a plane-wave pseudopotential scheme within linear response density-functional theory, as implemented in the QUANTUM-ESPRESSO package. The local density approximation (LDA) exchange-correlation function was employed. The Troullier-Martins normcon pseudopotentials were generated with valence atomic configurations of $3 \mathrm{~s} 2 \mathrm{p}$, $2 \mathrm{~s}^{2} 2 \mathrm{p}^{4}$ and $2 \mathrm{~s}^{2} 2 \mathrm{p}^{2}$ for $\mathrm{Al}, \mathrm{O}$ and $\mathrm{C}$, respectively. The electronic wave

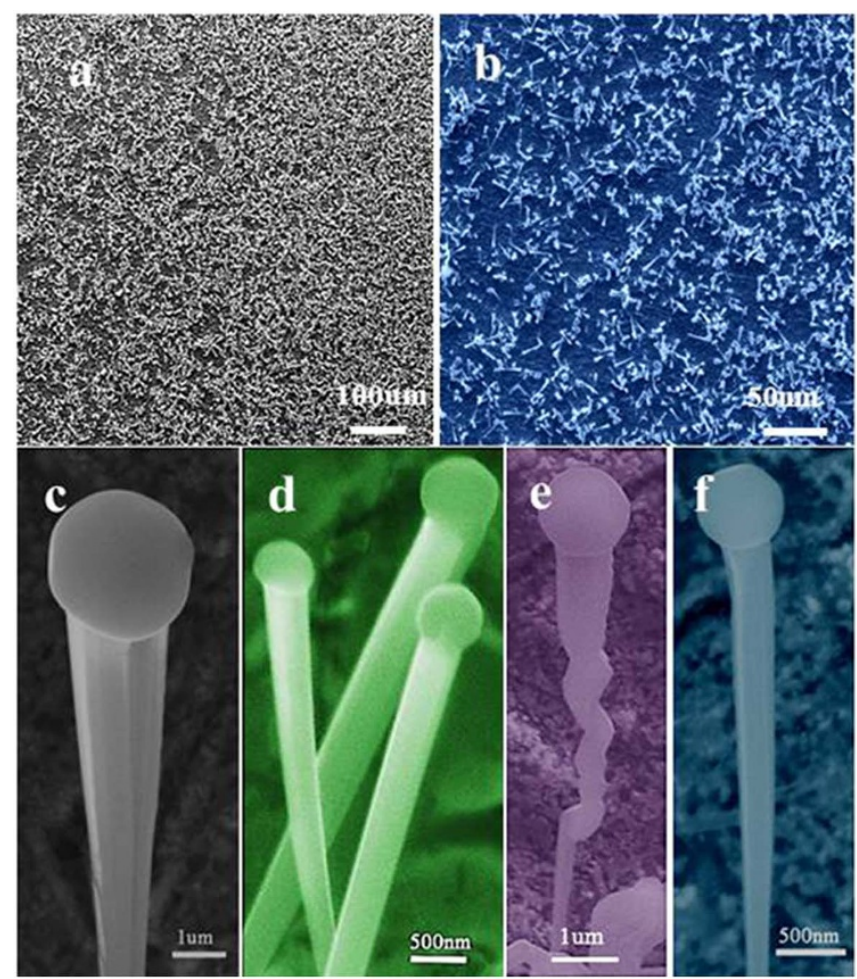

Figure $1 \mid$ SEM images of the as-synthesised sample. (a, b) Lowmagnification images of the product. (c-e) High-magnification images of needle wires with different sizes.

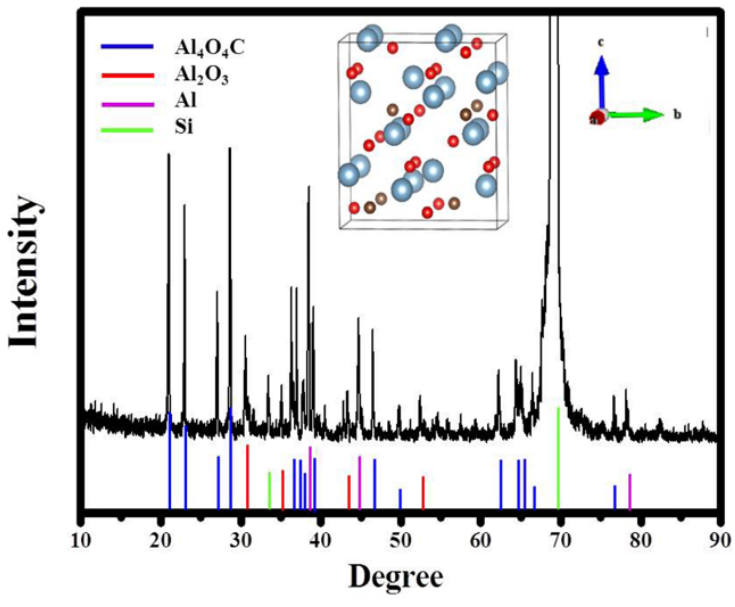

Figure $2 \mid$ XRD analysis of the product after it was transferred from the ceramic sheet to the silicon substrate. The inset shows the optimised structure of $\mathrm{Al}_{4} \mathrm{O}_{4} \mathrm{C}$.

functions and the electron density were expanded by the plane-wave basis sets with a cut-off energy of 70 Ry. Convergence tests indicated that $9 \times 6 \times 6$ Monkhorst-Pack grids in the Brillouin zone were required to obtain a total energy convergence better than $2 \mathrm{meV} /$ atom. In addition, the choices of the above computational parameters ensured that the convergence of the phonon frequencies were within $0.08 \mathrm{THz}$. The Raman intensities were computed from the second-order derivative of the electronic density matrix with respect to a uniform electric field. The Raman spectrum calculated with $10 \mathrm{~cm}^{-1}$ Gaussian smearing is shown in Fig. 3b. These Raman spectra indicate that $\mathrm{Al}_{4} \mathrm{O}_{4} \mathrm{C}$ has very rich molecular vibrational energy levels, which leads to complicated Raman modes. In addition, the experimental spectrum was obtained using a $514 \mathrm{~nm}$ laser as the excited source directed at a single needle, as shown in the inset of Fig. 3a. The experimental result is in good agreement with the

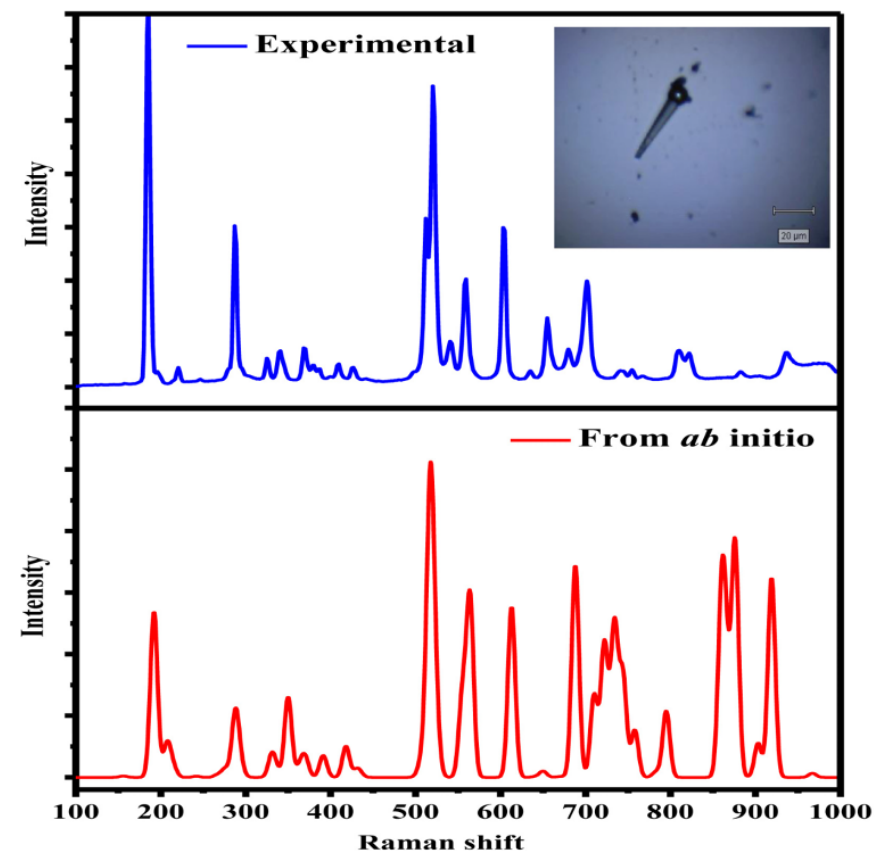

Figure 3 Raman investigation of the $\mathrm{Al}_{4} \mathrm{O}_{4} \mathrm{C}$ phase. (a) The Raman spectrum collected from a single $\mathrm{Al}_{4} \mathrm{O}_{4} \mathrm{C}$ needle using a 514-nm laser as the excitation source. (b) The Raman spectrum obtained from ab initio calculations. 
calculated result. Most of the main vibration modes share the same position even though several vibration modes shifted slightly.

To investigate the crystal structure of a single structure, TEM (transmission electron microscopy) analysis was performed, and the results are shown in Fig. 4. Fig. 4a shows the bright-field lowmagnification image of a single wire, and the inset is the SAED (selected area electron diffraction) pattern, which indicates a high degree of crystallinity. A corresponding high-resolution TEM image of an $\mathrm{Al}_{4} \mathrm{O}_{4} \mathrm{C}$ wire with large d-spacing and clear lattice sites is shown in Fig. 4b. Notably, our TEM is equipped with magnetic inclination. Therefore, the low-magnification image and the HRTEM image do not have the same orientation. According to the XRD results and the HRTEM analyses, we can easily conclude that the wire is orthorhombic $\mathrm{Al}_{4} \mathrm{O}_{4} \mathrm{C}$, and the stack direction is indicated in Fig. $4 \mathrm{~b}$. EDS elemental mapping analysis of a piece of the wire was performed during the TEM analysis. Figs. 4(d-f) display the elemental distribution along the wire corresponding to $\mathrm{O}, \mathrm{C}$ and $\mathrm{Al}$; on the basis of these results, the three elements are distributed symmetrically across the whole wire. To confirm its structure and explore the growth mechanism, we employed SAED at the catalytic head, as shown in Fig. 4h. Combined with the EDS analysis in Fig. 4i, we determined that the catalyst is primarily composed of metallic $\mathrm{Al}$, which is the origin of the $\mathrm{Al}$ signal in the XRD result.

Growth mechanism of needle micro-nano $\mathrm{Al}_{4} \mathrm{O}_{4} \mathrm{C}$ structures. On the basis of the previously described series of experiments and characterisations, we hypothesised that the formation of the $\mathrm{Al}_{4} \mathrm{O}_{4} \mathrm{C}$ needle wires occurs via the vapour-liquid-solid growth (VLS) mechanism. However, some differences were observed compared to the conventional VLS mechanism, which states that a nanowire is catalysed by an alloying droplet through active atoms precipitating from the liquid droplet ${ }^{15,16}$. Here, the catalytic $\mathrm{Al}$ droplets play an important role in collecting various clusters, such

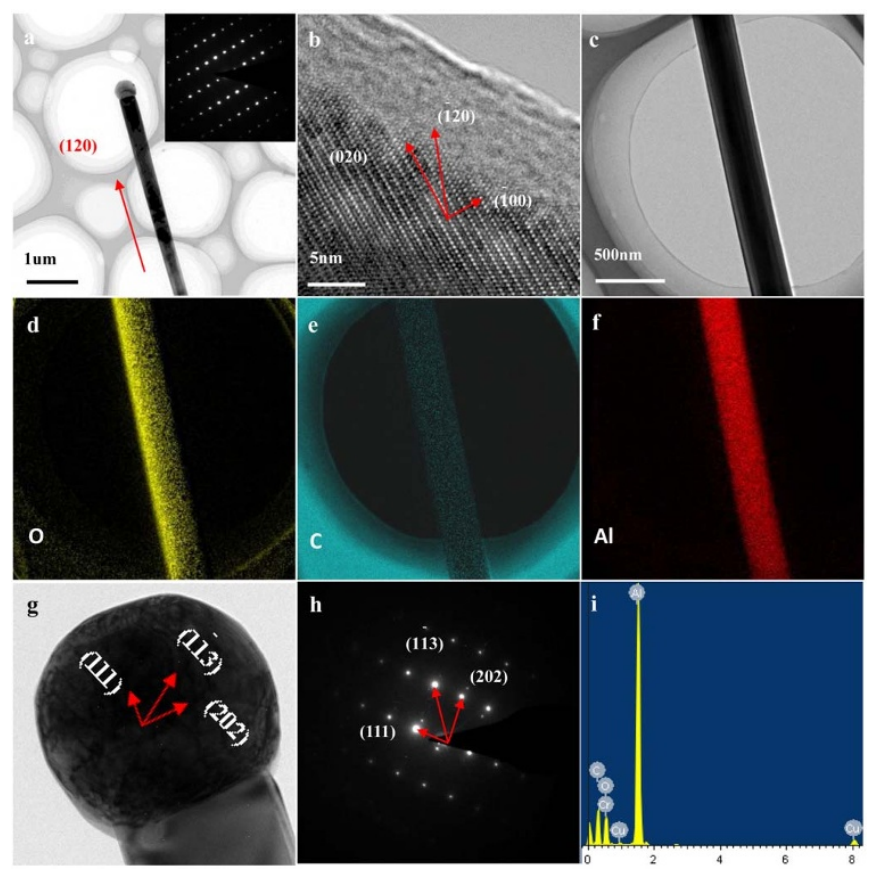

Figure $4 \mid$ TEM analysis of a single $\mathrm{Al}_{4} \mathrm{O}_{4} \mathrm{C}$ wire. (a) The low magnification image of the wire used in the analysis. The inset shows the SAED pattern of the wire. (b) Corresponding HRTEM image of the wire. (c) The piece of nanowire chosen for EELS mapping analysis.

(d-f) Elemental distribution of $\mathrm{O}, \mathrm{C}$ and $\mathrm{Al}$ obtained from the EELS mapping analysis. (g) The low-magnification image of the catalytic head of the analysed wire. (h) The SAED pattern of the head, which was confirmed to be metallic Al. (i) The EDS result for the catalytic head. as $\mathrm{Al}, \mathrm{C}, \mathrm{Al}_{2} \mathrm{O}_{3}$ and $\mathrm{Al}_{4} \mathrm{O}_{4} \mathrm{C}$, via surface absorption and serve as the reaction sites. In detail, when the temperature is increased to more than $800^{\circ} \mathrm{C}^{17}$, the $\mathrm{Al}$ atoms evaporate from the $\mathrm{Al}$ sheet and integrate as droplets in a low-temperature zone. At the same time, when the temperature is greater than $1000^{\circ} \mathrm{C}$ active carbon atoms form in the atmosphere due to $\mathrm{CH}_{4}$ cracking $^{18}$. In this case, there are various atomic radicals, including $\mathrm{Al}, \mathrm{AlO}_{\mathrm{x}}, \mathrm{C}, \mathrm{Al}_{4} \mathrm{O}_{4} \mathrm{C}$ and perhaps other $\mathrm{Al}-\mathrm{C}-\mathrm{O}$-based clusters, are present in the atmosphere. Through a series of reactions, a stable $\mathrm{Al}_{4} \mathrm{O}_{4} \mathrm{C}$ phase eventually forms. The $\mathrm{Al}_{4} \mathrm{O}_{4} \mathrm{C}$ molecules and clusters are collected by the liquid $\mathrm{Al}$ droplet via surface absorption and float on the surface of the $\mathrm{Al}$ liquid, which nucleates and grows larger at suitable sites as they coalesce together continuously. Simultaneously, excess Al atoms also combine with the liquid Al droplet. Therefore, the sizes of the catalytic $\mathrm{Al}$ heads increase, which results in nanowires with needle shapes. The detailed growth process is illustrated in Fig. S2 (Supplementary). In this process, $\mathrm{Al}$ heads play a critical role in inducing the one-dimensional growth of $\mathrm{Al}_{4} \mathrm{O}_{4} \mathrm{C}$ and in adjusting the size of the nanowires to themselves. If the nanowire and the $\mathrm{Al}$ head do not have axial symmetry, the nanowire deviates from its original growth tendency and changes its axial symmetry to adapt to the Al droplet. The change in axial symmetry of the nanowire can be attributed to two factors: I. Al droplets in the liquid state are not stationary; however, they frequently change their shapes and positions. II. The sites with more $\mathrm{Al}_{4} \mathrm{O}_{4} \mathrm{C}$ clusters grow faster, which influences the axial symmetry. Therefore, it is common for some nanowires to grow with several warps or in a zigzag shape, as shown in Fig. 1. The prepared $\mathrm{Al}_{4} \mathrm{O}_{4}$ micro-nano needle wires are shown on a blank area of the ceramic sheet as black ellipses in Fig. S2 (Supplementary).

\section{Discussion}

The synthesised $\mathrm{Al}_{4} \mathrm{O}_{4} \mathrm{C}$ needle wires were first characterised using the photoluminescence (PL) method. In the experiment, the sample was excited by a xenon lamp light source, and the emission signal was collected by a blue-sensitive light detector. The sample can be excited by $266 \mathrm{~nm}$ light, which results in the emission of intense blue light with wavelengths that range from $350 \mathrm{~nm}$ to $550 \mathrm{~nm}$ with an emission peak at $415 \mathrm{~nm}$. Fig. 5a contains two curves: the left one is the excitation spectrum, and the right one corresponds to the emission signal. Notably, even under irradiation by a xenon lamp, the bright emission area in blue is visible, as shown in the inset in Fig. 5a. This result indicates that $\mathrm{Al}_{4} \mathrm{O}_{4} \mathrm{C}$ is an excellent blue emitter with a high emission efficiency. Next, the temperature-dependent emission behaviour was investigated. Emission spectra at different temperatures that ranged from $12 \mathrm{~K}$ to $360 \mathrm{~K}$ under the same excitation conditions were obtained and are shown in Fig. 5 b. All of the spectra have the same profile, and no emission shift was detected, which further implies that the material exhibits stable blue light emission upon temperature variation. The emission intensity increases from $360 \mathrm{~K}$ to $12 \mathrm{~K}$, which is the phenomenon expected to result from the low nonradiative loss of photon energy at low temperatures. The acute peak located at approximately $455 \mathrm{~nm}$ is not the emission signal from the sample; it is rather an unwanted signal from the xenon lamp due to the absence of a filter. In this experiment, no filter was added to facilitate the accurate detection of the emission signal and to avoid any influence of a filter plate in the detection of weak signals at higher temperatures.

To further analyse the band structure with greater accuracy and to trace the PL origin, we performed $a b$ initio structural relaxations and electronic band structure calculations in the framework of density functional theory within the generalised gradients approximations (GGA) and the all-electron projector-augmented wave (PAW) method, as implemented in the VASP code. The PAW potentials were taken from the VASP library in which $3 \mathrm{~s} 2 \mathrm{p}, 2 \mathrm{~s} 22 \mathrm{p} 4$ and $2 \mathrm{~s} 22 \mathrm{p} 2$ are treated as valence electrons for $\mathrm{Al}, \mathrm{O}$ and $\mathrm{C}$ atoms, 

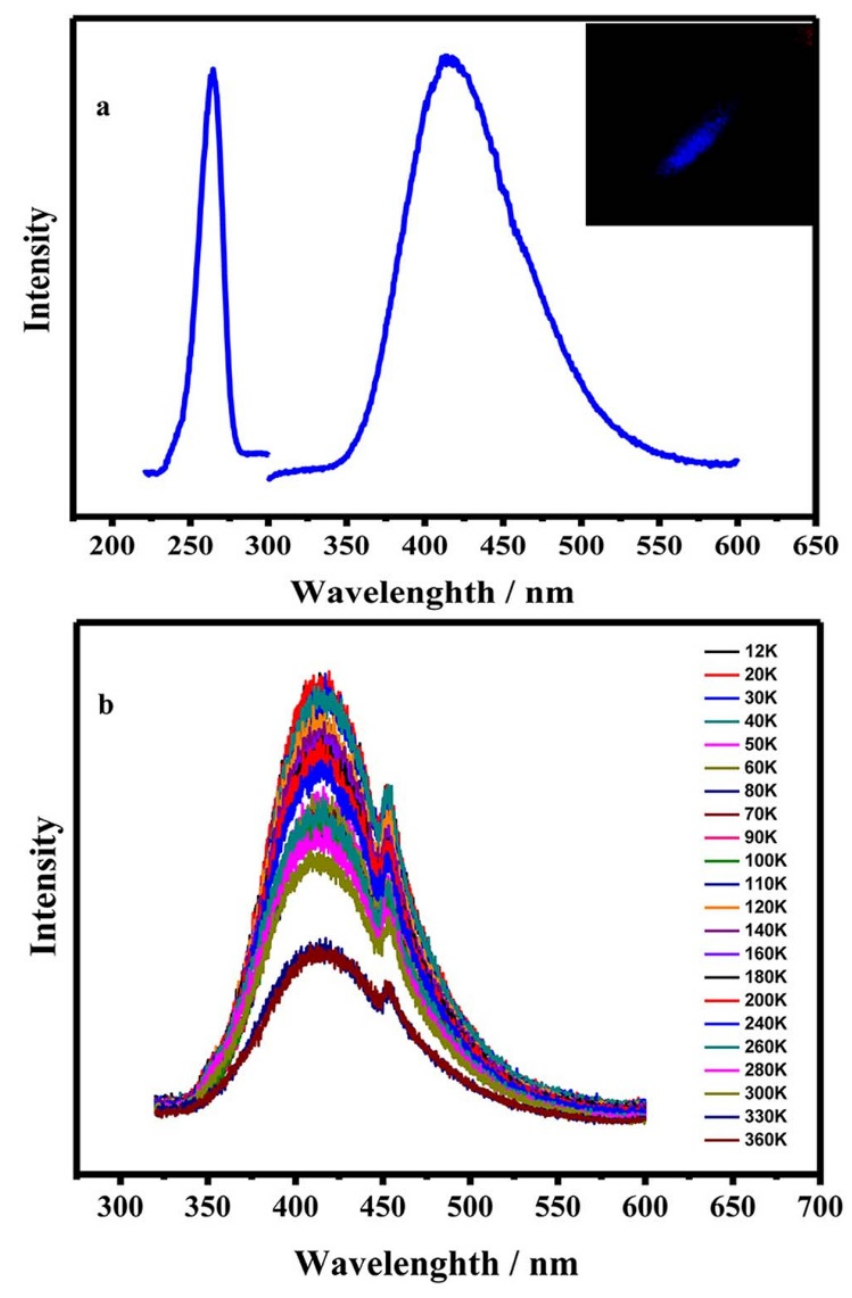

Figure $5 \mid$ PL properties at various temperatures under excitation by a 266-nm xenon lamp. (a) The blue emission behaviour of the assynthesised sample at room temperature. The left is the emission spectrum, and the right is the excitation spectrum. The inset shows the optical image captured by a common camera during the luminescence process. (b) The emission behaviour of the sample at different temperatures, which ranged from $12 \mathrm{~K}$ to $360 \mathrm{~K}$. The acute peak located at $455 \mathrm{~nm}$ corresponds to an unwanted light signal from the xenon lamp source.

respectively. The cut-off energy for the expansion of the wavefunctions into plane waves was set to $800 \mathrm{eV}$ in this calculation, and appropriate Monkhorst-Pack k meshes $(9 \times 6 \times 6)$ were chosen to ensure that enthalpy calculations were well converged. The band structure shown in Fig. S3 (Supplementary) was obtained from these calculations. The conduction band minimum is located at the $\mathrm{G}$ point, and the band gap was determined to be $3.8 \mathrm{eV}$, which is approximately $0.8 \mathrm{eV}$ higher than the energy of the emitting photons because of the differences between the ideal model and the real sample.

To investigate the light emission behaviour of a single needle, we employed microdomain PL analysis under a confocal microscope equipped with an ultraviolet lens and a CCD using a $325 \mathrm{~nm}$ laser as the excitation source. Due to the design of the light path, the ultraviolet light beam from the laser source converged to a light spot with diameter of approximately $2 \mu \mathrm{m}$. In this case, it was possible to obtain the light-emission information from a single wire. Fig. 6a shows the image captured by the CCD, where we chose a needle wire with a length of approximately $50 \mu \mathrm{m}$ and a diameter of the thick end of approximately $5 \mu \mathrm{m}$ to obtain a reliable emission signal. The inset in Fig. 6a shows the dark-field image of the needle excited by the

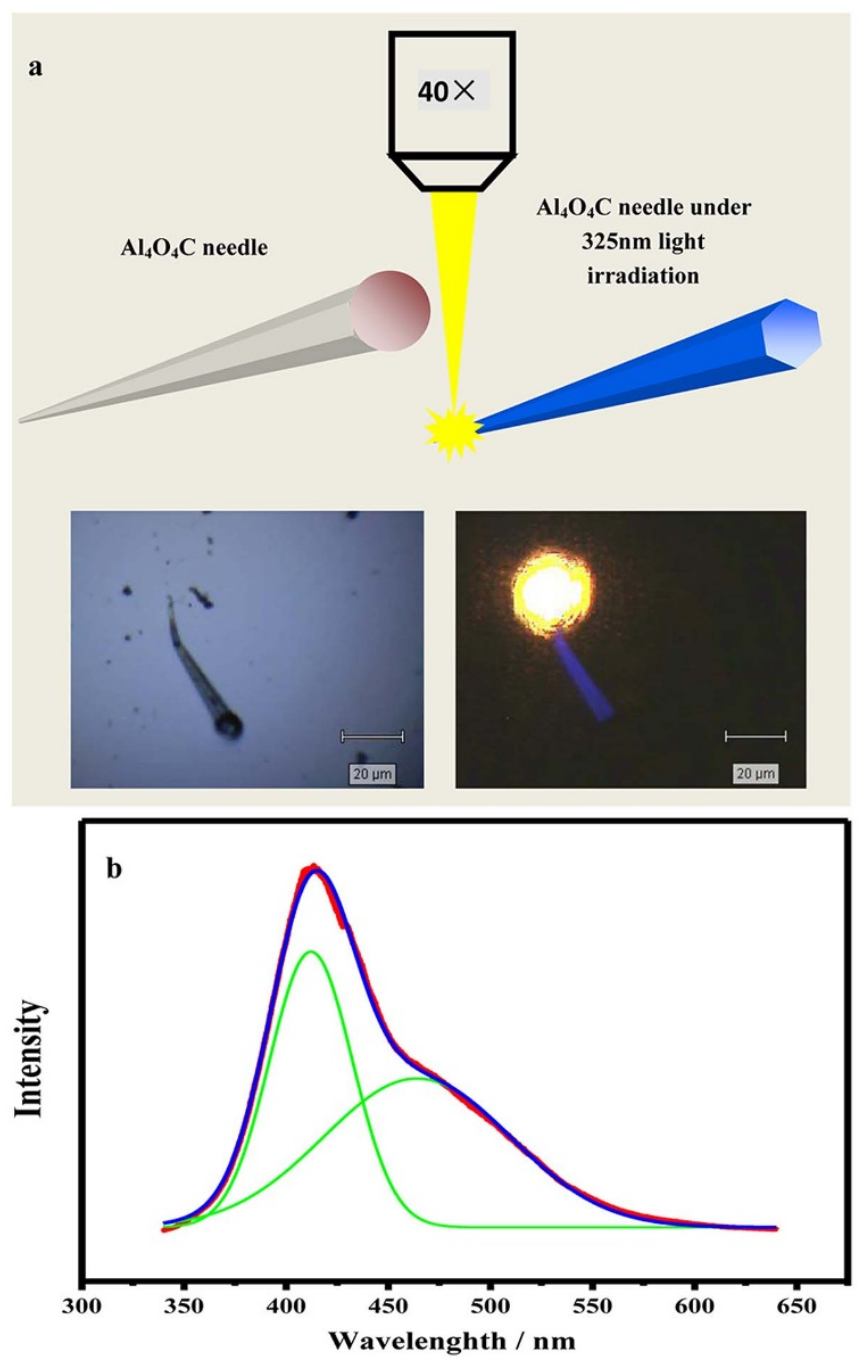

Figure 6 | The light emission behaviour of a single needle wire excited by a 325-nm laser. (a) Illustration of the experimental process. The insets display the image of the wire and blue body illuminated by the emitted light. The yellow light is not the real signal but is rather the trace of the 325nm light recorded by the CCD. (b) The spectrum of the needle excited by the $325-\mathrm{nm}$ laser recorded by the spectrometer.

$325 \mathrm{~nm}$ light spot. Although the light spot was focused on the thinner end of the needle, the entire wire displayed blue except for the catalyst area, which indicates the excellent light waveguide property of $\mathrm{Al}_{4} \mathrm{O}_{4} \mathrm{C}$. All of these advantages suggest the potential application of the ceramic $\mathrm{Al}_{4} \mathrm{O}_{4} \mathrm{C}$ needle wire as a micro-nano blue light source with a controllable size prepared via the growth of needle wires with different diameters. Figure $\mathbf{6 b}$ displays the emission spectrum of the single needle wire. This emission spectrum contains two peaks located at $415 \mathrm{~nm}$ and $464 \mathrm{~nm}$, which is similar to the spectrum excited by the 266-nm xenon lamp. The $464 \mathrm{~nm}$ light emission can be attributed to electron transition relative to the defect energy level.

Except in the PL analysis, we applied a cathode electron beam to excite a single wire under a scanning electron microscope operating platform, and the results are shown in Fig. 7. Two needle wires with different sizes were chosen for CL characterisation, and the resulting images are shown in Fig. 7a. There is a high contrast ratio between the bodies of the wires and the background, which implies intense fluorescence behaviour of the bright area. By collecting the fluorescence emission information with the assembled spectrometer, we obtained the emission spectrum, which is shown in Fig. 7a. This emission spectrum is the same as the PL result when the sample 

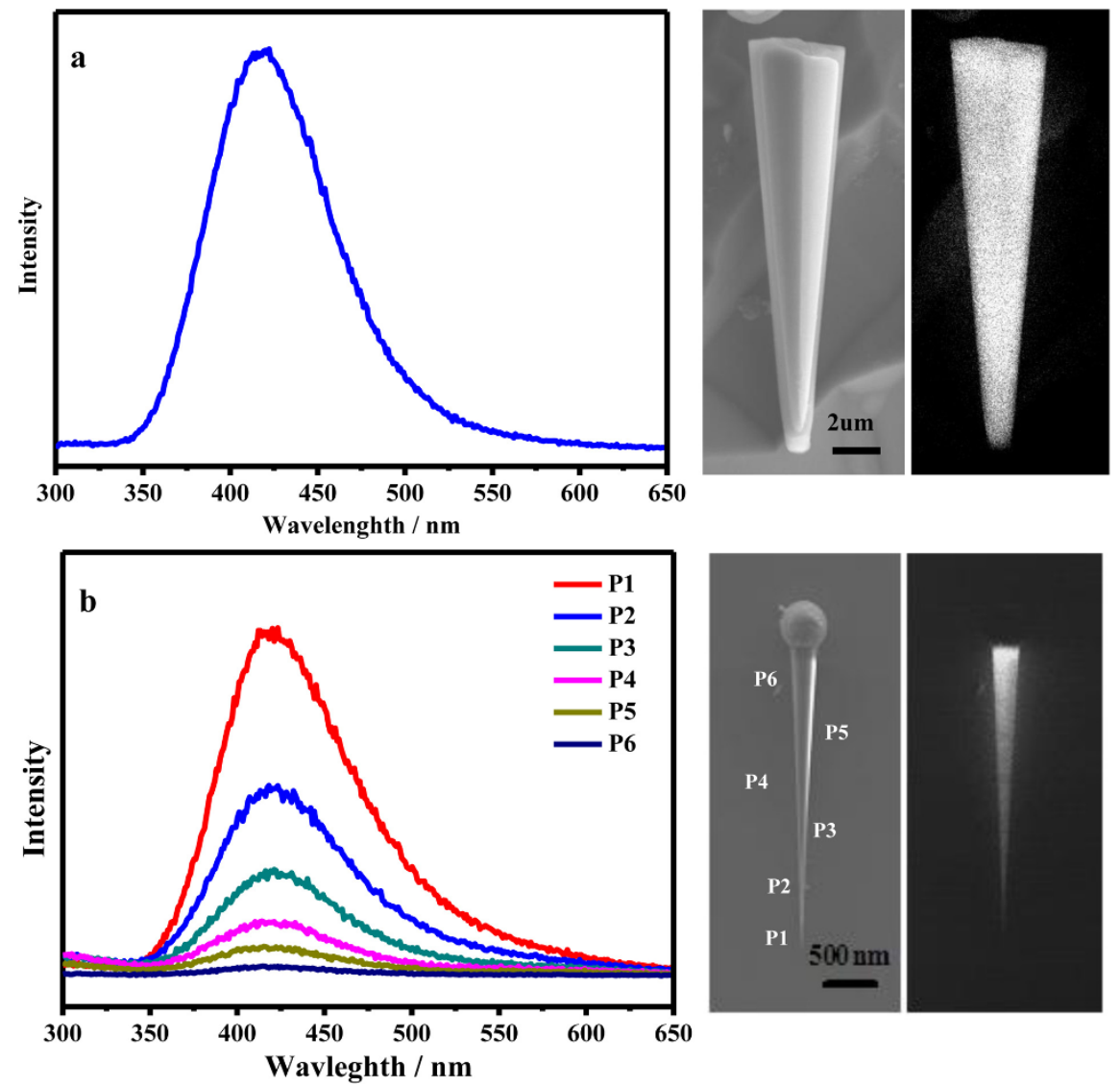

Figure $7 \mid$ The CL performance of a single needle. (a) The emission spectrum of a single $\mathrm{Al}_{4} \mathrm{O}_{4} \mathrm{C}$ needle along with the corresponding SEM image and CL emission image. (b) The CL emission spectrum for six positions with different sizes of a thinner needle. The right shows the corresponding SEM image and the emission profile.

was excited by the 266-nm radiation from the xenon lamp. The cathode electron beam with its low accelerated voltage excited the $\mathrm{Al}_{4} \mathrm{O}_{4} \mathrm{C}$ wires, which indicates that this ternary ceramic material is appropriate for use as a blue light source excited by a low-energy electron beam. In addition, to investigate the size dependent emission behaviour, we focused the electron beam on several sites with varying diameters, and the results are shown in Fig. $7 \mathbf{b}$. The emission spectra for all of the spots exhibited the same behaviour even though the intensities varied, which demonstrates the stability of the light emission and transportation upon size variation.

Based on the previously described light emission investigation, the $\mathrm{Al}_{4} \mathrm{O}_{4} \mathrm{C}$ micro-nano structures could be easily excited by a $266-\mathrm{nm}$ xenon lamp, a $325-\mathrm{nm}$ laser beam or a low-energy electron beam, resulting in stable emission of intense blue light irrespective of the size and temperature, which was as low as $12 \mathrm{~K}$. Considering the needle profile and the excellent waveguide property of $\mathrm{Al}_{4} \mathrm{O}_{4} \mathrm{C}$, we hypothesised that a very intense blue light nanobeam could be obtained from the thin end of the needle. First, we focused the 325-nm light spot on the thick end and observed the optical image through the CCD. As shown in Fig. 8a, the thin end was the brightest region along the needle. This result may be due to the highly efficient emission of the thick end or, as a consequence of the needle profile, the restriction of the light when the light is transported along the needle. Although there is loss due to scattering at the interface between the structure and air, we believe it is possible to obtain a nanosize light beam with high intensity due to the converging effect, which is illustrated in Fig. 8b.

In summary, the structural ceramic material $\mathrm{Al}_{4} \mathrm{O}_{4} \mathrm{C}$ has not attracted much attention for photoelectric applications. In this work, we synthesised $\mathrm{Al}_{4} \mathrm{O}_{4} \mathrm{C}$ needle wires via the CVD method in a high-vacuum reaction chamber and demonstrated its blue emission $\mathbf{a}$

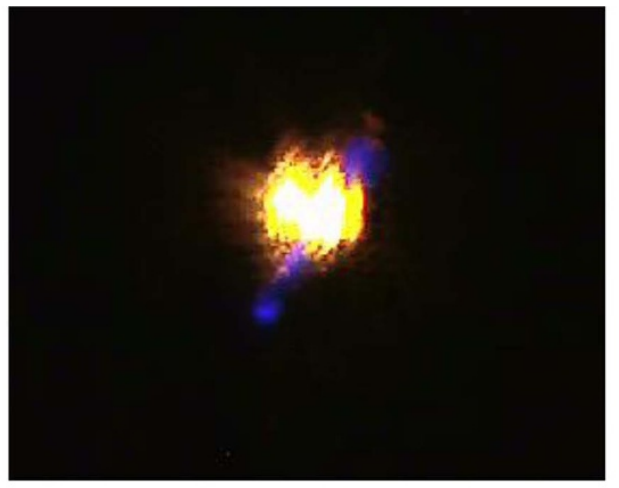

b

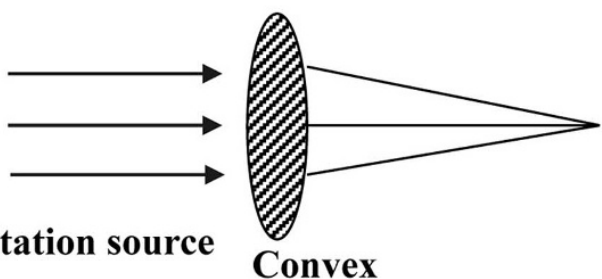

\section{Excitation source Convex}

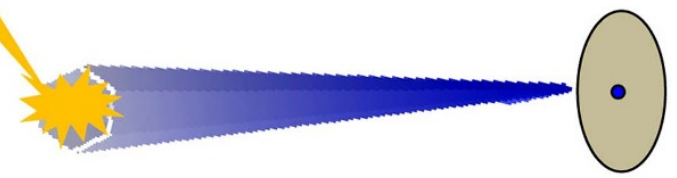

Figure $8 \mid$ Interesting convex effect from a single needle. (a) The luminescence image exhibits the highest emission intensity at the thin end of the needle even though it is excited at the thick end. (b) The convexeffect illustration that corresponds to (a). 
behaviour. Different methods were employed to excite a single wire. The $\mathrm{Al}_{4} \mathrm{O}_{4} \mathrm{C}$ was found to be an excellent blue light source as well as a potential candidate use as a light waveguide material. In addition, the Raman spectrum and band structure were determined using $a b$ initio calculations. We expect that $\mathrm{Al}_{4} \mathrm{O}_{4} \mathrm{C}$ could be used in future photoelectric devices and as a micro-nano light source.

\section{Methods}

Synthesis of $\mathrm{Al}_{4} \mathrm{O}_{4} \mathrm{C}$ needle. The $\mathrm{Al}_{4} \mathrm{O}_{4} \mathrm{C}$ micro-nano structures were prepared in a horizontal tube furnace connected to a turbo molecular pump. After the pre-vacuum procedure, the backing pressure of the reaction chamber was as high as $2 \times 10^{-5} \mathrm{~Pa}$. The illustration of the furnace is shown in Fig. S1 (Supplementary). The starting materials were placed on a ceramic plate $(160 \mathrm{~mm} \times 10 \mathrm{~mm} \times 1 \mathrm{~mm})$, which is a Five Aluminium $(\mathrm{Al})$ sheet $(10 \times 10 \times 0.5 \mathrm{~mm})$ located symmetrically on the right side of the ceramic plate that was more than $12 \mathrm{~cm}$ in length. The whole setup was placed in a semi-closed corundum protective tube with the idle load side towards the open end. Then, the corundum protective tube was pushed into the furnace. After the pre-vacuum process, the tube was heated to $1310^{\circ} \mathrm{C}$ stepwise over a period of 60 minutes. The temperature was subsequently held at $1310^{\circ} \mathrm{C}$ for 120 minutes. When the temperature was increased to $350^{\circ} \mathrm{C}, \mathrm{CH}_{4}$ and $\mathrm{H}_{2}$ were simultaneously introduced at a flow of $5 \mathrm{sccm}$ and $100 \mathrm{sccm}$, respectively, and the chamber pressure was maintained at $500 \mathrm{~Pa}$ until the temperature-control process was completed. Then, the chamber was rapidly cooled to room temperature using a water-cycling system. Micro-nano $\mathrm{Al}_{4} \mathrm{O}_{4} \mathrm{C}$ needle structures were found on the blank side of the ceramic plate, as shown.

Structural and photoluminescence characterizations. The crystal structure and the phase of the synthesized product was characterized using X-ray diffraction (XRD, Bruker D8 Advance). The morphology was investigated by field emission scanning electron microscope (FESEM, FEI Quanta 400F). The micro-structure analysis was further employed using high resolution transmission electron microscope (HRTEM, FEI Tecnai G2 F30). The photoluminescence test using Xenon lamp as excitation light source was carried out by applying Combined Fluorescence Lifetime and Steady State Spectrometer (EDINBURGH INSTRUMENTS LTD FLS920). Raman analysis and photoluminescence test upon a single needle was done on Laser Micro-Raman Spectrometer (Renishaw inVia) analysis platform.

1. Wang, R. C., Lin, H. Y., Wang, C. H. \& Liu, C. P. Fabrication of a large-area Aldoped $\mathrm{ZnO}$ nanowire array photosensor with enhanced photoresponse by straining. Adv. Funct. Mater. 22, 3875-3881 (2012).

2. Zhang, Y. et al. Scanning probe study on the piezotronic effect in $\mathrm{ZnO}$ nanomaterials and nanodevices. Adv. Mater. 24, 4647-4655 (2012).

3. Chen, G. et al. Resistive switching and magnetic modulation in Cobalt-doped ZnO. Adv. Mater. 24, 3515-3520 (2012).

4. Qi, J. et al. Resistive switching in single epitaxial $\mathrm{ZnO}$ nanoislands. ACS nano. 6 , 1051-1058 (2012).

5. Wang, N. W. et al. General strategy for nanoscopic light source fabrication. $A d v$. Mater. 23, 2937-2940 (2011).

6. Akasaka, T., Gotoh, H., Kobayashi, Y. \& Yamamoto, H. Extremely narrow violet photoluminescence line from iltrathin InN single quantum well on step-free GaN surface. Adv. Mater. 24, 4296-4300 (2012).

7. Chen, C. Y. et al. Gallium nitride nanowire based nanogenerators and lightemitting diodes. ACS nano. 6, 5687-5692 (2012).
8. Yoo, H. et al. Microstructures of GaN thin films grown on graphene layers. $A d v$ Mater. 24, 515-518 (2012).

9. Sun, Y. et al. Carbon-in- $\mathrm{Al}_{4} \mathrm{C}_{3}$ nanowire superstructures for field emitters. ACS nano. 5, 932-941 (2011).

10. Sun, Y. et al. Field nanoemitter: one-dimension $\mathrm{Al}_{4} \mathrm{C}_{3}$ ceramics. Nanoscale. 3 , 2978-2982 (2011).

11. Sun, Y., Cui, H., Gong, L., Chen, J. \& Wang, C. X. Synthesis of $\mathrm{Al}_{4} \mathrm{C}_{3}$ nanowalls via thermal evaporation and potential application in vacuum microelectronic devices as cold electron emitters. CrystEngComm. 14, 7951-7957 (2012).

12. Cui, H. et al. Ultralong one-dimension $\mathrm{A}_{13} \mathrm{CON}$ nanostructures: synthesis, elastic deformation behavior and photoelectric properties. J. Mater. Chem. 22, 1283012836 (2012)

13. Zhao, J. L., Lin, W., Yamaguchi, A., Ommyoji, J. J. \& Sun, J. L. Influence of heating temperature, keeping time and raw material grain size on $\mathrm{Al}_{4} \mathrm{O}_{4} \mathrm{C}$ synthesis in carbon thermal reduction process and oxidation of $\mathrm{Al}_{4} \mathrm{O}_{4}$ C. J. Ceram. Soc. Jpn. 115, 654-660 (2007)

14. Lihrmann, J. M. Thermodynamics of the $\mathrm{Al}_{2} \mathrm{O}_{3}-\mathrm{Al}_{4} \mathrm{C}_{3}$ system: $\mathrm{I}$. Thermochemical functions of $\mathrm{Al}$ oxide, carbide and oxycarbides between 298 and 2100 K. J. Eur. Ceram. Soc. 28, 633-642 (2008).

15. Sun, Y. et al. The synthesis and mechanism investigations of morphology controllable 1-D SiC nanostructures via a novelapproach. Cryst Eng Comm. 12, 1134-1138 (2010).

16. Alegria, L. D. et al. Structural and electrical characterization of Bi2Se3 nanostructures grown by metal-organic chemical vapor deposition. Nano lett. 12, 4711-4714 (2012).

17. Sun, Y., Cui, H., Jin, S. X. \& Wang, C. X. Eutectic solidification applied to nanofabrication: a strategy to prepare large-scale tungsten carbide nanowalls. J. Mater. Chem. 22, 16566-16571 (2012).

18. Rizk, S. et al. Synthesis of carbon coated $\beta-S i C$ nanofibers by microwave plasma assisted chemical vapour deposition in $\mathrm{CH}_{4} / \mathrm{H}_{2}$ gas mixture. Diamond Relat. Mater. 17, 1660-1665 (2008).

\section{Acknowledgements}

This work was financially supported by the National Nature Science Foundation of China $(51125008,11274392)$

\section{Author contributions}

C.-X. W. conceived and provided critical ideas for the work. Y. S. and C.-R. D. performed the optical experiments, including the results shown in Figures 5, 6 and 8. Y.-Z. C. and Y.-M. M. performed $\mathrm{ab}$ initio calculations to generate the Raman spectra and electronic structures shown in Figures 3 and Figure S3 (Supplementary). G.-W. Y. analysed the experimental results. Y. S. and C.-X. W. performed analyses and wrote the manuscript.

\section{Additional information}

Supplementary information accompanies this paper at http://www.nature.com/ scientificreports

Competing financial interests: The authors declare no competing financial interests. License: This work is licensed under a Creative Commons Attribution-NonCommercial-NoDerivs 3.0 Unported License. To view a copy of this license, visit http://creativecommons.org/licenses/by-nc-nd/3.0/

How to cite this article: Sun, Y. et al. One-Dimensional $\mathrm{Al}_{4} \mathrm{O}_{4} \mathrm{C}$ Ceramics: A New Type of Blue Light Emitter. Sci. Rep. 3, 1749; DOI:10.1038/srep01749 (2013). 